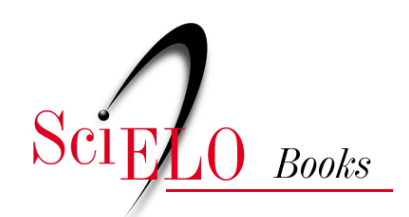

Editora da UESC

\title{
A relação sujeito e mundo na fenomenologia de Merleau-Ponty
}

\author{
Antonio Balbino Marçal Lima
}

\section{SciELO Books / SciELO Livros / SciELO Libros}

LIMA, ABM., org. A relação sujeito e mundo na fenomenologia de Merleau-Ponty. In: Ensaios sobre fenomenologia: Husserl, Heidegger e Merleau-Ponty [online]. Ilhéus, BA: Editus, 2014, pp. 77-102. ISBN 978-85-7455-444-0. Available from SciELO Books <http://books.scielo.org>.

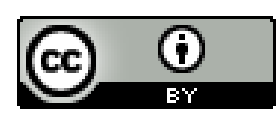

All the contents of this work, except where otherwise noted, is licensed under a Creative Commons Attribution $\underline{4.0 \text { International license. }}$

Todo o conteúdo deste trabalho, exceto quando houver ressalva, é publicado sob a licença Creative Commons Atribição 4.0.

Todo el contenido de esta obra, excepto donde se indique lo contrario, está bajo licencia de la licencia Creative Commons Reconocimento 4.0. 


\title{
A relação sujeito e mundo na fenomenologia de Merleau-Ponț
}

Antonio Balbino Marçal Lima

\section{$1 \mathrm{O}$ conceito de sujeito na fenomenologia de Merleau-Ponty}

\author{
$\mathrm{O}$ verdadeiro cogito não \\ substitui o próprio mundo \\ pela significação do mundo.
}

Merleau-Ponty

O presente texto visa apresentar a fenomenologia de Merleau-Ponty a partir de um ponto de vista que, segundo o próprio autor, é constante na tradição filosófica: trata-se da relação sujeito e mundo, ou seja, de entender as relaçôes entre a consciência e natureza, o interior e o exterior. Para tanto, é necessário fazer uma descrição da concepção de sujeito para a tradição filosófica, remontando ao sujeito moderno, principalmente às tradiçóes cartesiana e kantiana.

A questão da subjetividade na modernidade ${ }^{1}$ é marcada

1 Modernidade aqui entendendo o período que começa com Descartes e termina com Hegel (N. A.). 
por um dualismo: por um lado, o racionalismo, que enfatiza a subjetividade do Eu, por outro, os empiristas, que objetivam o Eu. O distintivo fundamental entre racionalismo e empirismo é que enquanto o empirismo afirma que a origem fundamental de todo o conhecimento está localizado na observação, os racionalistas insistem que tal origem se dá nos atos de apreensão do puro intelecto, ou como afirma Descartes, nas "ideias claras e distintas". Segundo Bicca, (1997, p. 146) o termo "sujeito":

Adquire foro de elemento de linguagem filosófica a partir e no sentido da tradiçâo latina (subjectum) do grego (hypokeimenon), cujo significado filosófico principal foi cunhado por Aristóteles: o que está na base ou por baixo, o que porta ou é suporte de, daí ser traduzido também por substrato ou até mesmo por substância.

$\mathrm{Na}$ modernidade, o conceito de sujeito ora significa o ser do homem como um todo, isto é, sujeito empírico que é união do corpo e da alma, ora designa o contrário, aquela estrutura formal da subjetividade, acessível apenas por meio da autorreflexão intelectual. Essa dicotomia está, portanto, no cerne das discussóes que contrapóem o racionalismo ao empirismo.

Para resolver essa discussão peculiar da modernidade, entre o lado intelectual e o lado sensível do sujeito, Kant tenta dar um novo sentido: mantendo do racionalismo o significado da atividade intelectual, do entendimento; do empirismo, retém a possibilidade das faculdades sensíveis.

$\mathrm{Na}$ modernidade há um deslocamento, antes o conhecimento era centrado no ser, que tinha uma existência autônoma, que era algo exterior ao homem a quem cabia apenas a 
função de reconhecimento e não de construção do saber; com "o penso, logo existo" de Descartes inaugura-se uma filosofia que tem como ponto de partida e como referência o homem interior, ou seja, a subjetividade, em outras palavras, há um deslocamento do ser para a consciência. Essa subjetividade originada do cartesianismo vai transformar o conhecimento da realidade, onde o real agora será apreendido pela consciência. Portanto, há uma separação entre sujeito e objeto, isto é, o objeto passa a ser algo que é representado por um sujeito que lhe confere sentido.

O que significa representação? A representação é entendida como processo pelo qual o sujeito se apropria do objeto, convertendo-o em ideia; a verdade é produzida pelo sujeito no processo de percepçáo do eu intelectual. A consciência, entendendo-a como capacidade de síntese, a partir de si mesma, passa a ser fundamento, certeza primeira, fonte das demais.

\subsection{O sujeito perceptivo}

Merleau-Ponty, na Fenomenologia da Percepção, afirma que quer se trate do empirismo ou idealismo, isto é, quer se afirme o sujeito como constituído pelo mundo ou o mundo como constituído pelo sujeito, a concepção clássica de mundo é a mesma: um mundo constituído por relaçóes objetivas.

Partia-se de um mundo em si que agia sobre nossos olhos para fazer-se ver por nós, tem-se agora uma consciência ou um pensamento do mundo, mas a própria natureza deste mundo não mudou: ele é sempre definido pela exterioridade absoluta das partes e apenas duplicado em toda a sua extensão 
por um pensamento que o constrói. Passa-se de uma objetividade absoluta a uma subjetividade absoluta, mas esta segunda idéia vale exatamente tanto quanto a primeira e só se sustenta contra ela, quer dizer, por ela (MERLEAU-PONTY, 1999, p. 69).

A partir desta citaçáo, pode-se entender porque, no prefácio à Fenomenologia da Percepção, Merleau-Ponty afirma que a fenomenologia é um desmentido da ciência, pois, trata-se de descrever, não de explicar o fenômeno da percepção. É partindo da crítica ao objetivismo e ao subjetivismo que ele justifica a volta aos fenômenos para a análise da percepção e do corpo próprio.

Merleau-Ponty não tem interesse em fundar uma filosofia do sujeito, pois, o ser é consagrado ao sentido, é um sujeito entrelaçado ao mundo. Não há um sujeito transcendental, puro; o homem é, ao mesmo tempo, "eu" corporal e sujeito pensante. O sujeito encontra-se afetado da presença íntima dos objetos. A filosofia não passa de um inventário da consciência como meio de universo. Com isso, caem os problemas da alma e do corpo. O corpo não é mais um mecanismo fechado sobre si, sobre o qual a alma agiria de forma como um motor.

Na Fenomenologia da Percepção, Merleau-Ponty insiste numa volta à experiência perceptiva, pois, segundo ele, a percepção real e a lógica vivida, com as quais se instaura nosso acesso ao mundo, foram esquecidas pela tradição filosófica. É na percepção que surge a significação fundamental como verdade implícita da existência. Perceber é, pois, uma atitude que se opóe ao representar ou instaurar um conhecimento objetivo.

Em Merleau-Ponty, o sujeito no mundo é o corpo no mundo, então o sujeito da percepção é o corpo, porque é ele que percebe, é ele que sente, é uma unidade perceptiva viva, 
e não mais a consciência concebida separadamente da experiência vivida, consciência da qual provém o conhecimento. $\mathrm{O}$ corpo é, então, visto como fonte de sentidos, ou seja, de significação da relação do sujeito com o mundo, porém, um sujeito visto na sua totalidade, na sua estrutura de relaçóes com as coisas ao seu redor, com as coisas que nos cercam. Ao falar da percepção, Merleau-Ponty chama a atenção para o fato de que o que é percebido por uma pessoa (fenômeno) acontece num campo do qual ele faz parte. Ao considerar o sujeito como corpo no mundo, Merleau-Ponty assinala a importância da experiência perceptiva e nos mostra que o conhecimento começa no corpo-próprio.

A experiência perceptiva é corporal, nasce da relação do corpo com o mundo e não de uma associação, feita pela consciência, que vem dos órgãos dos sentidos, a partir daí podese dizer que o corpo é visto numa totalidade. O sujeito não é um observador (transcendental, no sentido kantiano) nem a consciência é uma consciência testemunha. Para Merleau-Ponty, é a percepção, como ato inaugural, e não o sujeito da consciência representativa que nos abre o sentido dos dados percebidos. A percepção "correta" ou "falsa" da coisa se constrói na relação que se inaugura entre o corpo e o mundo e não através de uma ideia da realidade previamente estabelecida na consciência.

Diferentemente da tradição moderna, Merleau-Ponty mostra na Fenomenologia da Percepção, que a consciência não se define como cogito e faculdade intelectual da representação, mas como percepção. Isso quer dizer que a tradição filosófica sempre opôs a percepção, conhecimento sensível, ao pensamento. Considerando a percepção confusa, vaga e inadequada; e o pensamento claro, distinto e evidente. Como consequência 
dessa visão tem-se a concepção de mundo como uma realidade em si, autônoma e objetiva, que pode ser alcançada pela consciência por meio da representação, operação que passa do mundo à ideia do mundo, transformando o mundo em ideia. Merleau-Ponty desloca o conhecimento e a relação consciência-mundo para a percepção; segundo ele, a percepção não é uma ciência do mundo, ela é o fundo sobre o qual se destacam todos os atos e é pressuposto por eles. $\mathrm{O}$ mundo é o meio natural e o campo de todos os meus pensamentos e de todas as minhas percepçóes explícitas, assim o mundo não pode ser um objeto cuja constituição possuo em meu íntimo:

A verdade não 'habita' apenas o 'homem interior', ou, antes, não existe homem interior, o homem está no mundo, é no mundo que ele se conhece. Quando volto a mim a partir do dogmatismo do senso comum ou do dogmatismo da ciência, encontro não um foco de verdade intrínseca, mas um sujeito consagrado ao mundo (MERLEAU-PONTY, 1999, p. 6 , grifos do autor).

A partir da citação acima pode-se compreender que há em Merleau-Ponty uma recusa da filosofia da consciência, entendendo consciência como sujeito transcendental ou espírito como interioridade absoluta consigo mesmo, uma consciência constituinte. Merleau-Ponty vai se referir a uma consciência perceptiva, como sujeito de um comportamento, como ser no mundo ou existência. Para ele, a consciência só é pensável a partir da compreensão de que 'consciência' é estar na coisa por intermédio de um corpo. Aos poucos Merleau-Ponty já não fala em consciência, mas em percepção. Segundo ele, sujeito e objeto são construçóes tardias da Filosofia e da Ciência, que não traduzem a dinâmica da existência humana. 
A percepção não é a revelação subjetiva de uma qualidade sensível, é a colocação de um objeto no espaço, uma mesa a um metro de mim, por exemplo, é objeto de minha percepção. Segundo a teoria intelectualista, a percepção é o ato pelo qual o indivíduo, organizando suas sensações presentes, interpretando-as e completando-as, opóe-se a um objeto que, espontaneamente, julga distinto de si, real e atualmente conhecido por ele.

Para os gestaltistas, de quem Merleau-Ponty aceita muitas ideias, a percepção não pode ser reduzida à associação de juízos e de raciocínios, "[...] o mundo percebido não é uma soma de objetos, no sentido que as ciências dão a esta palavra [...]” (MERLEAU-PONTY, 1990, p. 41). A percepção é, então, uma atitude originária, primitiva, uma relação imediata entre consciência concreta e o universo. Nesse sentido, Merleau-Ponty insiste no papel do sujeito corpóreo, como centro de perspectiva, na percepçáo. A organização global do campo perceptivo é efetuada pelo corpo-sujeito, em situação. A percepção não se dá, portanto, através de uma representação mais ou menos real do objeto, mas sim como a própria formação do sentido desse objeto. A percepção não é causada pelos objetos sobre nós, nem é causada pelo nosso corpo sobre as coisas: é a relação entre elas e nós e nós e elas; uma relação possível porque elas são corpos e nós também somos corporais. Para Merleau-Ponty (1999, p. 6), a percepção "não é uma ciência do mundo, não é nem mesmo um ato, uma tomada de posição deliberada; ela é o fundo sobre o qual todos os atos se destacam e é pressuposta por eles"; ela é, portanto, na fenomenologia de Merleau-Ponty, o acesso à experiência originária onde se unem a consciência e o mundo.

A tarefa da filosofia é descrever, não explicar ou analisar; a filosofia tem como tarefa reaprender a ver o mundo, porém 
não se trata de um empirismo, pois o homem é, ao mesmo tempo, eu corporal e sujeito pensante. A partir desta concepção caem os problemas da alma e do corpo, o corpo não é um mecanismo fechado sobre si, onde a alma agiria de fora como um motor; o corpo não é objeto, ele está comigo e pode tocarse tocando e nunca é completamente constituído.

\section{Imbrincamento do Sujeito e do Objeto no Corpo Próprio}

Perceber o mundo e não descrevêlo são possibilidades indissociáveis de nossa capacidade intelectiva [...] o conhecimento adequado supóe separação e distanciamento entre sujeito e objeto [...] avesso a essa simplificação epistemológica, compreendemos as coisas na medida em que nos movemos entre elas.

Após a crítica ao humanismo filosófico que, segundo Merleau-Ponty, foi o principal responsável pelo dualismo sujeito-objeto, passamos, agora, a análise da percepção e do corpo próprio, conceitos fundamentais da fenomenologia de Merleau-Ponty e mostraremos como se articulam esses temas na filosofia de Merleau-Ponty, evidenciando, portanto, como se dá a relaçáo do sujeito-mundo.

\subsection{A problemática do corpo e da percepção}

Merleau-Ponty, na obra Fenomenologia da Percepção, faz um estudo detalhado do corpo, ultrapassando tanto a concepção materialista da ciência positiva, que considera o corpo 
como um objeto, quanto a espiritualista que desconsiderava o corpo, fazendo oposição à alma. A tradição filosófica sempre considerou o corpo como objeto, realidade em si. Para Descartes a natureza própria do corpo é a extensão. Segundo a concepção de Merleau-Ponty, o corpo é uma totalidade, não é um objeto em si, mas um sujeito presente no mundo; a consciência perceptiva não é uma interioridade absoluta, mas uma presença corporal no mundo. Assim, o sujeito perceptivo é essencialmente um sujeito mundano.

Segundo Merleau-Ponty (1999) eu não tenho um corpo, eu sou o meu corpo, ou seja, sou o corpo que percebe e simultaneamente é percebido, portanto deve deixar de ser concebido como objeto, como coisa. É a partir do corpo próprio que estou no mundo, em relação com os outros e com as coisas, assim, o corpo não pode ser visto como um receptor passivo das coisas que nos rodeiam.

O corpo que percebe não é uma porção do espaço isolável numa extensão definida, "partes extra partes", nem meio ou instrumento, nem o centro de referência por uma alma desencarnada. O percebido é alcançado de maneira indivisível como em si, ou seja, como realidade dotada de um interior que nunca terminarei de explorar, e como para si, isto é, como realidade dada em pessoa através de seus aspectos momentâneos.

Merleau-Ponty desloca, portanto, o conhecimento e a relação consciência-mundo para a percepção quando no prefácio da Fenomenologia da Percepção afirma que

[...] a percepção não é uma ciência do mundo, não é nem mesmo um ato, uma tomada de posição deliberada; ela é o fundo sobre o qual todos os atos se destacam e ela é pressuposta por eles (1999, p. 6). 
Nesse sentido, prossegue o filósofo afirmando que o mundo não é um objeto do qual possuo comigo a lei de constituição; ele é o meio natural e o campo de todos os meus pensamentos de todas as minhas percepçóes explícitas. A percepção, então, não é um produto do mundo, um esboço da ciência do mundo, como também a plena consciência de si não está toda feita está por se fazer, realizar-se na existência.

Segundo Merleau-Ponty (1999) é o ato preceptivo que faz surgir o mundo que então aparece tal como foi percebido, ou seja, como mundo fenomenal; para ele, é a percepção que nos dá acesso às próprias coisas e o mundo real. Merleau-Ponty compreende a percepçáo como uma experiência onde se une consciência-mundo, e assim ela coincide com essa experiência constituindo-se como fundamento daquele que percebe e do que é percebido, uma vez que ambos surgem em mútua união; o processo perceptivo, então, é a síntese sujeito-mundo, vivência verdadeira de uma unidade (corpo próprio), dada imediatamente e anterior à reflexão. Portanto,

não podemos, em conseqüência, aplicar à percepção a distinção clássica de matéria e forma nem conceber o sujeito que percebe como uma consciência que 'interpreta', 'decifra', ou 'ordena' uma matéria sensível da qual possuiria a lei ideal (MERLEAU-PONTY, 1990, p. 41, grifos do autor).

A percepção, diz Merleau-Ponty, não é uma operação intelectual; a operação perceptiva se realiza a partir do corpo, uma intencionalidade silenciosa, fundadora, operante, isto é, 
a percepção no estado nascente está se realizando desde o meu contato inicial com o mundo. A análise perceptiva mostra também que o sujeito efetivo da percepção é o corpo.

\subsection{O corpo como fundador do conhecimento}

O corpo é, para Merleau-Ponty, o meio por excelência de acesso ao mundo, ou seja, o corpo é o mediador de toda experiência possível. O corpo, então, é o mediador do mundo, isto é, um sistema aberto sobre o mundo e a operação perceptiva se realiza a partir do corpo, a percepção no seu estado nascente realiza desde o seu contato inicial com o mundo. A descrição perceptiva revela também que é o corpo o sujeito efetivo da percepção; contudo, considerar o corpo como sujeito da percepção não significa conferir-lhe poderes de um pensamento constitutivo, mas, sim, atribuir-lhe uma potencialidade original.

Na Fenomenologia da percepção, o trabalho de Merleau-Ponty é mostrar que o corpo não é coisa, nem ideia, mas movimento, sensibilidade e expressão criadora. Opondo-se à perspectiva mecanicista da Filosofia e da Ciência tradicionais ${ }^{2}$ e alinhando-se a uma nova compreensão do corpo e do movimento humano, baseando-se na compreensão das relaçôes corpo-mente como unidade e não como integração de partes distintas.

2 A perspectiva tradicional da Ciência e da Filosofia é aqui considerada como centradas no sujeito, no ego ou na razão como centro do conhecimento, colocando o corpo e os sentidos como elementos acessórios no processo de conhecimento e até mesmo causadores de erros; bem como aquelas centradas no objeto, desconsiderando a subjetividade (N. do A.). 
$\mathrm{Na}$ tentativa de superar a dicotomia sujeito-objeto, Merleau-Ponty afirma que o homem é essencialmente corpoconsciência-do-mundo, o corpo é mundo e alma simultaneamente, o corpo do homem não é nem pura coisa nem a pura ideia, ele integra misteriosamente o percebido e o ato de perceber, o em si e o para si, pois está no mundo e é para o mundo; póe-nos em contato com o mundo e ao mesmo tempo é o modo segundo o qual nos revela ao mundo.

Criticando as compreensóes de corpo presentes no empirismo e no intelectualismo, Merleau-Ponty afirma que, na perspectiva fenomenológica, o corpo é compreendido, não como objeto ou um modo do espaço objetivo, tal como o concebe a fisiologia mecanicista, que reduz a açáo ao esquema estímulo-resposta e a percepção como ordenadora do sensível; nem a partir da ideia de corpo, como o faz a Psicologia Clássica, mas a partir da experiência vivida. "O corpo objetivo não é a verdade do corpo fenomenal" (MERLEAU-PONTY, 1999, p. 578), afirma o filósofo ao criticar a perspectiva da ciência clássica, fundada na causalidade linear, no esquema mecanicista do estímulo-resposta. Merleau-Ponty apresenta uma visão de corpo diferente da tradição cartesiana: nem coisa, nem ideia, o corpo está associado à motricidade, à percepção, à sexualidade, à linguagem, ao mito, à experiência vivida, à poesia, ao sensível e ao invisível, apresentando-se como um fenômeno complexo, não se reduzindo à perspectiva de objeto, fragmento do mundo, regido pelas leis de movimento da mecânica clássica, submetido à leis e estruturas matemáticas exatas e invariáveis (MERLEAU-PONTY, 1999).

Corpo e consciência não são causalidades distintas, mas uma unidade expressa pela dinâmica da experiência do corpo em movimento: "O corpo assim compreendido revelará o 
sujeito que percebe assim como o mundo percebido" (MERLEAU-PONTY, 1999, p. 110). Assim, ao criticar as análises tradicionais acerca do corpo, do movimento e da percepção, Merleau-Ponty enfatiza a experiência corporal fundada numa perspectiva sensível da corporeidade, buscando ultrapassar a dicotomia sujeito/objeto.

A expressão "sou meu corpo" (MERLEAU-PONTY, 1999, p. 208) sintetiza o encontro entre o sujeito e o corpo. Ao incluir a dimensão existencial, Merleau-Ponty busca ampliar as noções objetivistas das ciências. Por isso, não se contenta em inventariar partes do corpo ou estabelecer uma imagem ou ideia do corpo em movimento, mas enfatiza a vivência como situação original e significativa da existência. Diante da fragmentação da análise científica clássica, ele considera necessário construir novos conceitos que ampliem a compreensão da existência, a partir da vivência corpórea. Nesse sentido, apresenta a noção de corpo-próprio como a realidade intencional do sujeito, em contraponto à noçáo cartesiana de corpo-máquina, ou corpo-objeto, buscando superar a perspectiva do discurso que privilegia a causalidade e que coloca o corpo como inferior à consciência ou aos procedimentos racionais.

O corpo não é uma massa material inerte, sendo a causalidade linear, baseada no esquema estímulo-resposta, não se apresenta como a maneira mais apropriada de compreensão do universo corpóreo. Por sua vez, a sensação e a percepção não são elementos inferiores à evidência racional, aos conceitos lógico-matemáticos, sendo imprescindíveis ao processo de conhecimento. Com esses argumentos, busca esclarecer a relação entre corpo e consciência, inaugurando uma nova possibilidade de compreensão deste fenômeno, a análise existencial, 
privilegiando o mundo das experiências vividas como plano primeiro da configuração do ser e do conhecimento.

Baseando-se na Fisiologia, na Psicologia e na Física Modernas, Merleau-Ponty (1999) busca ultrapassar as relaçôes de causalidade, argumentando que, na compreensão dos fenômenos, não se admite uma explicação puramente fisiológica, psicológica ou mista, mas da ordem do ser no mundo. Para o filósofo, a experiência do corpo revela um modo de existência profundamente significativo, a vivência: "Quer se trate do corpo do outro ou de meu próprio corpo, não tenho outro meio de conhecer o corpo humano senão vivê-lo" (MERLEAU-PONTY, 1999, p. 269).

Diante da insuficiência da objetividade científica e do idealismo metafísico, Merleau-Ponty busca uma nova forma para refletir sobre a condição humana, enfatizando a experiência e a relação entre o organismo e a consciência, não os reconhecendo como causalidades distintas. $\mathrm{O}$ organismo não é uma coisa inerte, mas esboça o movimento da existência e, posto que há sentidos, não existem movimentos em si no nosso corpo:

Nessa medida, até mesmo os reflexos têm um sentido, e o estilo de cada indivíduo ainda é visível neles, assim como o batimento do coraçáo se faz sentir até na periferia do corpo (MERLEAU-PONTY, 1999, p. 126).

O ser humano define-se pelo corpo, isto significa que a subjetividade coincide com os processos corporais. Mas, é preciso considerar que: "ser corpo é estar atado a um certo mundo” (MERLEAU-PONTY, 1999, p. 205). Na perspectiva fenomenológica, a dimensão essencial só apresenta senti- 
do se unida à dimensão existencial, ao mundo vivido. Essência e existência apresentam-se como dimensóes de um mesmo fenômeno, o ser humano.

\section{Referências}

BICCA, L. Racionalidade moderna e crise. São Paulo: Loyola, 1997.

CHÂTELET, F. História da filosofia: idéias e doutrinas, o século XX. Tradução Hilton Japiassú. São Paulo: Zahar, 1974.

DARTIGUES, A. O que é a fenomenologia. 3. ed. Tradução Maria José J. G. de Almeida. São Paulo: Editora Moraes, 1992.

FRAGATA, J. A filosofia de Merleau-Ponty. Revista Portuguesa de Filosofia, Braga, n. 29, p.113-141, abr.-jun. 1963.

GILES, T. R. Crítica fenomenológica da psicologia experimental em Merleau-Ponty. Petrópolis: Vozes, 1979.

MERLEAU-PONTY, M. Fenomenologia da percepção. Tradução Carlos Alberto Ribeiro de Moura. São Paulo: Martins Fontes, 1999.

. Ciências do homem e fenomenologia. Tradução Selma Tannus. São Paulo: Saraiva, 1973.

. Elogio da Filosofia. 5. ed. Tradução António Braz Teixeira. Lisboa: Guimarães Editores, 1998. 
Antonio Balbino Marçal Lima

MERLEAU-PONTY, M. O primado da percepçáo e suas conseqüências filosóficas. Traduçáo Constança Marcondes César. Campinas: Papirus, 1990.

MOURA, C. A. R. de. Racionalidade e crise: estudos de história da filosofia moderna e contemporânea: São Paulo: Discurso Editorial, 2001.

SAMABRIA, J. R. Maurice Merleau-Ponty: fenomenólogo existencial. Revista de Filosofia, México, D. F.,núm.61, p. 23-44 jan.-abr. 1988. 